\title{
Implikasi Gaya Pembelajaran Koperatif Subjek Sains Bagi Murid Tahap Dua di Sekolah Kebangsaan Bandar Baru Rawang
}

\author{
Nadia Abdul Rahim ${ }^{1}$, Nor Aqilah Meor Fadzir ${ }^{1}$, Nur Adilah Hani Zaimal ${ }^{1}$, Firli Fairulyzan \\ Arias Yahaya ${ }^{1}$, Zatul Iffah Zainol ${ }^{1}$, Mohd Razimi Husin ${ }^{1}$
}

${ }^{1}$ Fakulti Pembangunan Manusia, Universiti Pendidikan Sultan Idris. Perak, Malaysia.

\author{
Article History \\ Received: \\ 16.07.2021
}

Revised:

28.07.2021

Accepted:

09.08.2021

*Corresponding Author:

Mohd Razimi Husin

Email:

razimi@fpm.upsi.edu.my

This is an open access article, licensed under: $\mathrm{CC}-\mathrm{BY}-\mathrm{SA}$
Abstrak: Kajian ini adalah sebuah kajian bagi meneroka ekologi pendidikan secara spesifik. Di mana, kajian ini adalah berfokuskan kepada Implikasi Gaya Pembelajaran Koperatif dalam Stimulus Sosial terhadap pembelajaran subjek Sains. Kajian ini adalah kajian kualitatif yang bercirikan Kajian Kes. Kajian ini telah dijalankan di salah sebuah sekolah rendah di kawasan Rawang, Selangor. Responden yang terlibat dalam kajian ini adalah seorang Guru Sains, yang berpengalaman mengajar selama 16 tahun. Proses perolehan data pula, diperolehi melalui sesi temu bual bersama responden melalui kaedah temu bual separa berstruktur. Instrumen kajian yang digunakan adalah 10 soalan temu bual yang dirangka selari dengan persoalan kajian. Dapatan kajian yang diperoleh, menjelaskan bahawa, gaya pembelajaran koperatif dapat menarik minat serta pemahaman murid tahap dua dalam mata pelajaran Sains. Malah ia dapat menampilkan ciri ciri murid yang memenuhi kehendak aspirasi pendidikan negara. Ini adalah kerana, kemahiran komunikasi dan interaksi, kemahiran berfikir secara kreatif dan kritis, kemahiran penyelesaian masalah, kemahiran bekerja dalam kumpulan, kemahiran bersosial dan nilainilai sosial serta kepimpinan dapat diterapkan secara tidak langsung dalam pelaksanaan pengajaran dan pembelajaran koperatif.

Kata Kunci: Implikasi Pembelajaran, Pembelajaran Abad Ke-21, Pembelajaran Koperatif.

Implications of Cooperative Learning Style of Science Subjects for Level Two Students in Sekolah Kebangsaan Bandar Baru Rawang

Abstract: This study is a study to explore the ecology of education specifically. Where, this study is focused on the Implications of Cooperative Learning Style in Social Stimulus on the learning of Science subjects. This study is a qualitative study characterized by a Case Study. This study was conducted in one of the primary schools in Rawang, Selangor. The respondent involved in this study was a Science Teacher, with 16 years of teaching experience. The data acquisition process, on the other hand, was obtained through an interview session with the respondents through a semi structured interview method. The research instrument used was 10 interview questions designed in parallel with the research questions. The findings of the study, explain that, cooperative learning style can attract the interest and understanding of level two students in the subject of Science. In fact, it can feature the characteristics of students who meet the needs of the country's educational aspirations. This is because, communication and interaction skills, creative and critical thinking skills, problem solving skills, group work skills, social skills and social values as well as leadership can be applied indirectly in the implementation of cooperative teaching and learning.

Keywords: Learning Implications, 21st Century Learning, Cooperative Learning. 
Nadia Abdul Rahim, Nor Aqilah Meor Fadzir, Nur Adilah Hani Zaimal, Firli Fairulyzan Arias Yahaya, Zatul Iffah Zainol, Mohd Razimi Husin.

\section{Pengenalan}

Seiring dengan ledakan globalisasi masa kini, Negara Malaysia dilihat turut berkembang pesat. Justeru Malaysia perlu membawa suatu perubahan yang akan memberikan impak yang besar dalam dunia pendidikan dalam mencapai ke tahap pendidikan bertaraf dunia. Kementerian Pendidikan Malaysia (KPM) telah mengkaji dan meneliti elemen-elemen yang perlu dilaksanakan dalam menjayakan inisiatif tersebut. Pembelajaran Abad ke-21 (PAK21) yang dilancarkan pada 2014 merupakan hasil daripada penelitian tersebut dan kini, PAK21 telah menjadi satu isu hangat dalam dunia pendidikan. Ini adalah kerana ianya dilihat dapat memenuhi keperluan pendidikan masa kini dan pada masa yang sama membawa kepada perubahan baharu dalam dunia pendidikan. PAK21 adalah satu proses pembelajaran yang berpusatkan kepada murid yang menitikberatkan penglibatan aktif murid-murid dalam pembelajaran. Dalam PAK21 ini guru-guru lebih banyak memainkan peranan sebagai fasilitator dan pengurus dalam bilik darjah bagi memastikan ianya bersesuaian dengan persekitaran sepertimana di alam pekerjaan. Umumnya, PAK 21 merupakan strategi pembelajaran yang menggunakan pendekatan-pendekatan yang terkini demi memastikan penglibatan aktif dalam pembelajaran. Dalam PAK21 terdapat beberapa elemen yang diterapkan dan dijadikan standard asas PAK21 iaitu pemikiran kritis, kreativiti, komunikasi, kolaboratif, koperatif serta aplikasi etika dan nilai-nilai murni.

Komunikasi secara umumnya merupakan satu proses dimana pertukaran maklumat antara dua atau lebih individu berlaku. Dalam PAK21 elemen komunikasi merujuk kepada hubungan dua hala diantara tenaga pengajar denga murid/ pelajar atau diantara murid dengan murid dalam usaha untuk berkongsi ilmu agar dapat difahami bersama-sama. Komunikasi diantara murid-murid mahupun gurumurid bagi tujuan perkongsian ilmu ini dikatakan sebagai komunikasi berpusatkan murid. Komunikasi jenis ini memerlukan para guru untuk memainkan peranan dengan efektif bagi memastikan komunikasi ini berlangsung dengan berkesan. Antara kaedah yang boleh digunakan oleh tenaga pengajar dalam mewujudkan komunikasi dua hala adalah dengan meminta murid-murid mengadakan perbentangan berkumpulan mengenai sesuatu tajuk. Melalui cara ini, murid-murid akan mengadakan perbincangan dengan ahli kumpulan masing-masing sebelum perbentangan dilakukan. Pada masa yang sama juga, para guru atau tenaga pengajar turut memainkan peranan sebagai fasilitator kepada para pelajar dengan memantau cara penyampaian murid-murid bagi memastikan keberkesanan perbentangan sekaligus memberikan input yang berkualiti kepada para murid yang lain. Dari sudut pembangunan murid itu secara peribadinya, para guru boleh memberikan kritikan yang membina daripada segi penggunaan bahasa badan, nada suara, tulisan serta cara bertanya, cara menjawab persoalan serta memberikan maklumbalas yang berkaitan. Justeru murid-murid akan dapat membina keyakinan diri semasa berinteraksi dengan rakan dengan cara mendengar dan memberikan maklumbalas

Antara elemen penting dalam PAK21 adalah elemen kolaboratif, yang merujuk kepada sesuatu aktiviti yang dilaksanakan bersama-sama atau secara berkumpulan. Dalam aspek pendidikan, kolaboratif merupakan kerjasama yang wujud diantara tenaga pengajar dengan murid atau diantara murid dengan murid secara aktif dan menyeluruh yang mana ianya berfokuskan kepada pertukaran idea, pandangan mahupun info diantara murid-murid tersebut. Amat penting dalam aspek ini untuk guru-guru memahami dan memberikan tumpuan kepada gaya pembelajaran murid-muridnya. Tidak dapat dinafikan bahawa terdapat individu dalam kalangan para murid yang tidak gemar melakukan tugasan mahupun aktiviti secara berkumpulan. Ini berikutan beberapa faktor, antaranya adalah hubungan yang tidak mesra diantara ahli kumpulan dan juga pendapat yang sering diketepikan. Dalam situasi ini, guru-guru perlu memainkan peranan dalam usaha menarik minat pelajar-pelajar ini dalam memastikan tugasan berkumpulan kelihatan menarik dan menyeronokkan. Suasana pembelajaran yang kolaboratif akan membawa kepada metakognitif yang merupakan kesedaran murid-murid tentang perkara yang diketahui dan tidak diketahui semasa proses pembelajaran.

Dalam PAK21 penerapan elemen pemikiran kritis amat diberi perhatian. Pemikiran kiritis merujuk kepada keupayaan individu dalam membuat penilaian tentang sesuatu perkara termasuk melihat daripada sudut kebaikan dan keburukan perkara tersebut. Pemikiran kritis dalam aspek pendidikan berlaku apabila murid-murid mula meneroka pemikiran mereka bagi menilai pemikiran-pemikiran dan pandangan secara rasional dan seterusnya membuat pertimbangan mengenai idea-idea tersebut dengan mengaplikasikan alasan-alasan yang sewajarnya. Keberkesanan pemikiran kritis dapat berlaku dengan pelbagai kaedah. Antaranya adalah dengan penggunaan sumber yang meluas. Sumber yang meluas ini bermaksud maklumat yang diperolehi oleh murid-murid. Justeru para guru perlu memantau maklumat 
yang diperolehi oleh para murid ini bagi memastikan iainya bertepatan dengan topik yang sedang dipelajari. Para guru juga perlu memastikan para murid mahir dalam mencari maklumat yang berkaitan dan membuat penilaian terhadap maklumat yang diperolehi oleh murid ini. Pemikiran kritis juga akan lebih efektif apabila guru-guru tidak menghadkan pandangan atau pendapat daripada para murid. Dalam abad yang ke 21 ini, para guru wajar memberikan galakan kepada para murid untuk aktif memberikan pandangan terhadap topik yang sedang dibahaskan. Melalui kaedah ini para guru dapat membuat penilaian terhadap tahap pemikiran para murid terhadap perkara-perkara yang berkaitan dan dapat memastikan samada murid-murid tersebut dapat berfikir secara kritis. Antara pendekatan lain yang dapat diterapkan dalam mengasah pemikiran kritis ini adalah dengan mengalakan aspek perbahasan semasa PdP berlangsung. Dalam aspek ini, guru akan meminta murid untuk memberikan pandangan terhadap sesuatu tajuk dan selanjutnya memberikan alasan terhadap pandangan yang diberikan. Murid yang berfikiran kritis dapat dikatakan sebagai murid yang berfikiran terbuka. Ini adalah berdasarkan kerterbukaan mereka dalam menerima pandangan dan ideaidea yang dikemukakan oleh rakan-rakan yang lain dan tidak merendah-rendahkan idea-idea tersebut.

Kreativiti juga merupakan salah satu elemen dalam PAK21 yang amat penting. Kreativiti merujuk kepada sesuatu proses yang berlaku, dimana iainya melibatkan penghasilan sesuatu yang baharu, berguna dan berkualiti. Elemen ini merupakan satu elemen yang penting untuk diterapkan dalam diri murid kerana pemikiran diluar kotak akan dapat menjana sesuatu yang baharu dan berguna.

Strategi pembelajaran secara koperatif dan kolaboratif memerlukan pelajar untuk saling bekerjasama dalam kumpulan bagi menyelesaikan masalah, memberikan maklumbalas, serta saling berinteraksi antara satu sama lain dengan lebih berstruktur. Pembelajaran koperatif merupakan satu set proses yang dapat membantu pelajar untuk saling berinteraksi antara satu sama lain bagi mencapai matlamat khusus dalam sesuatu perkara. Menurut Kagan [1], aktiviti pembelajaran dikatakan wujud apabila sturktur koperatif disesuaikan dengan isi kandungan

Pembelajaran secara koperatif dapat meningkatkan potensi murid daripada segi pencapaian akademik. Ianya juga akan dapat meningkatkan kepekaan positif murid-murid dalam pelbagai pekara disamping dapat membantu mereka memantapkan kemahiran sosial. Sesuatu pembelajaran jenis koperatif yang menaplikasikan peraturan dalam bilik darjah akan mampu mewujudkan kerjasama satu pasukan yang efektif. Terdapat enam konsep utama dalam pembelajaran koperatif iaitu yang pertama adalah Pasukan yang memerlukan visi dan mempunyai struktur bagi membantu perkembangan minda yang positif, yang kedua adalah Kemahiran sosial, diikuti oleh pengurusan bilik darjah dan prinsip iaitu penggantungan positif, akauntabiliti penglibatan yang setara serta interaksi serentak, keazaman untuk bekerjasam serta akhir sekali struktur-struktur yang terentu.

Dalam membincangkan mengenai ciri-ciri pembelajaran koperatif, banyak pendapat telah dikongsi oleh para ilmuan antaranya adalah pembelajaran koperatif akan menjadi efektif apabila melibatkan ganjaran kumpulan, tanggung-jawab individu dan peluang yang sama untuk berjaya [2]. Sementara itu, Johnson \& Johnson [3] menggariskan lima ciri pembelajaran koperatif iaitu matlamat kumpulan, peranan ahli, interaksi, kemahiran berkumpulan dan penilaian berkumpulan.

Pembelajaran abad ke-21 (PAK 21) telah diperkenalkan oleh Kementerian Pendidikan Malaysia (KPM) dengan bermatlamatkan kearah peningkatan kualiti dalam sistem pendidikan melalui keberhasilan murid yang menguasai pengetahuan, kemahiran dan nilai. Ini termasuklah menjadikan para murid mampu untuk berdaya saing diperingkat antarabangsa dengan membentuk warganegara yang kritis, kreatif dan berketrampilan yang mengamalkan budaya sains dan teknologi. Pendidikan sains di Malaysia bertujuan bagi memupuk budaya sains dan memberikan tumpuan kepada perkembangan individu yang kompetitif, dinamik, tangkas dan berdaya tahan. Kurikulum sains digubal berlandaskan keperluan negara dan ciri sejagat sains iaitu dengan menintegrasikan perolehan dan aplikasi pengetahuan, penguasaan kemahiran dan penerapan sikap saintifik serta nilai-nilai murni untuk murid-murid dan pelajar di peringkat rendah dan menengah. Matapelajaran sains, mengikut Pekeliling Ikhtisas Bil 17/1988 memperuntukan selama 200 minit seminggu bagi proses pengajaran dan pembelajaran. Dalam tempoh yang diperuntukan ini, murid-murid diberi peluang untuk meneroka alam sekitar, membuat eksperimen dan mempelajari kemahiran-kemahiran baharu melalui cuba jaya dan meneroka dan menyiasat mengikut minat dan keinginan mereka.

Matapelajaran sains merupakan antara matapelajaran yang amat digeruni oleh para murid dan pelajar. Ini kerana matapelajaran ini memerlukan mereka untuk sentiasa fokus dan teliti untuk berupaya memahami matapelajaran tersebut. Para murid cenderung menjadi bosan dan kurang 
berminat untuk mempelajari subjek ini kerana memerlukan mereka untuk sentiasa fokus. Situasi ini memberikan impak yang tidak baik terhadap pencapaian mereka dalam subjek ini.

Kajian ini justeru, cuba untuk menilai, gaya pembelajaran yang menjadi pilihan guru dan murid dalam proses pembelajaran subjek sains dan untuk melihat samada penerapan gaya pembejaran tersebut akan membantu para pelajar untuk lebih melibatkan diri dalam matapelajaran ini dan selanjutnya membantu meningkatkan pencapaian mereka dalam matapelajaran sains.

Gaya pembelajaran merupakan satu elemen yang amat penting dalam memastikan keberhasilan pembelajaran oleh seseorang murid. Antara isu yang ketara dalam setiap pembelajaran adalah pencapaian pelajar yang kurang cemerlang, terutamanya dalam matapelajaran sains. Tidak dapat dinafikan setiap individu lahir dengan personaliti serta gaya tersendiri. Ini termasuklah dalam proses pembelajaran dimana para murid dan pelajar cenderung mempraktikan gaya pembelajaran yang sedia wujud dalam diri masing-masing dalam proses pembelajaran. Gaya pembelajaran ini merupakan satu faktor yang penting dalam memastikan keberhasilan pembelajaran dan seterusnya memberikan impak ke atas pencapaian akademik pelajar tersebut. Setiap murid mempunyai gaya pembelajaran yang berbeza, dan secara tidak langsung juga hasil pencapaian oleh mereka. Mata pelajaran sains merupakan satu subjek yang amat penting disekolah. Justeru, sekiranya murid gagal memberikan tumpuan dan perhatian tehadap matapelajaran ini, kebolehan mereka untuk mengusai subjek ini cenderung untuk menjadi sukar dan seterusnya mempengaruhi pencapaian akademik mereka.

Dalam kajian oleh Firdaus et al [4] yang menunjukkan bahawa minat pelajar terhadap matapelajaran sains adalah dipengaruhi oleh rakan sebaya dimana dalam kajian tersebut mendapati factor ini merupakan factor ketiga yang mempengaruhi pelajar kurang cemerlang dalam matapelajaran ini. Sementara itu dalam kajian oleh Kamisah et al. [5] didapati sikap pelajar terhadap matapelajaran Sains adalah rendah justeru membawa implikasi kepada keperluan mengubah corak pengajaran dan pembelajaran sains yang lebih bersifat inkuiri dan hands on.

Oleh yang demikian, kajian ini dijalankan bagi tujuan mencuba untuk memahami gaya pembelajaran koperatif yang sering menjadi pilihan guru matapelajaran sains tahap dua di sekolah rendah, tenang kenapa gaya pembelajaran tersebut digunapakai dan samada gaya pembelajaran koperatif tersebut dapat memberikan manfaat serta kepada para murid dan berkesan dalam menarik minat mereka mengikuti matapelajaran sains dan pada masa yang sama membantu para pelajar ini memperbaiki pencapaian mereka dalam matapejaran sains di sekolah. Manakala kajian oleh Bakar \& \& Mohammed [6] mencadangkan guru perlu mempelbagaikan pendekatan dalam pengajaran dan pembelajaran melalui penggunaan alat bantu mengajar yang lebih berkesan bagi megesan sebarang kekeliruan konsep semasa pengajaran.

\section{Sorotan Kajian Lampau}

Sains mempunyai peranan yang amat penting dalam memacu pembangunan negara. Kurikulum Sains di Malaysia digubal selari dengan hasrat dalam Falsafah Pendidikan Kebangsaan yang mementinhkan kesepaduan antara ilmu pengetahuan, sikap dan nilai-nilai murni [7]. Dalam pendidikan di Malaysia, matapelajaran sains memainkan peranan sebagai subjek teras di peringkat rendah dan menengah rendah. Diperingkat menengah atas, matapelajaran sains ditawarkan dalam Sains Teras, Sains Tambahan dan Sains Elektif yang meliputi Biologi, Kimia dan Fizik berdasarkan aliran yang dipilih.

Matapelajaran sains dapat menjadi satu subjek yang amat menarik apabila seseorang murid itu mempunyai minat dan semangat yang tinggi dalam berusaha memahami subjek ini. Namun dalam kebanyakkan situasi subjek ini merupakan mimpi ngeri murid-murid kerana memerlukan keupayaan kognisi yang mantap. Murid-murid akan cenderung untuk berasa bosan dan berputus asa dalam mendalami setiap topik yang dipelajari apabila mereka sukar memahami subjek tersebut.

\subsection{Pembelajaran Abad ke-21}

Iberahim et al [8] dalam kajian mereka yang bertajuk Pembelajaran Abad Ke-21 Dan Pengaruhnya Terhadap Sikap, Motivasi dan Pencapaian Bahasa Melayu Pelajar Sekolah Menengah mengatakan bahawa kemahiran abad-21 merupakan kemahiran pembelajaran yang amat penting dan sangat diperlukan oleh pelajar untuk berdaya saing dalam abad ini. Ini kerana kemahiran di abad 21 dikaitkan dengan pelbagai elemen yang diperlukan dalam zaman teknologi yang meliputi kemahiran komunikasi, kemahiran sains dan teknologi, kemahiran berfikir, kemahiran interpersonal dan intrapersonal, kemahiran 3M dan sebagainya. Dalam kajian ini, instrumen yang digunakan adalah jenis borang kaji selidik dan melibatkan seramai 277 responden yang merupakan pelajar tingkatan 
empat aliran sains dan swasta daripada tiga buah sekolah menengah di sekitar daerah Tanah Merah Kelantan. Objektif bagi kajian yang dijalankan ini adalah bagi mengenalpasti pengaruh pembelajaran abad ke-21 terhadap sikap, motivsasi dan pencapaian pelajar dalam subjek bahasa melayu. Dapatan daripada kajian ini menunjukkan pengaruh pembelajaran abad ke 21 ini banyak memberikan pengaruh yang postif terhadap sikap, motivasi dan pencapaian pelajar dalam mempelajari subjek Bahasa Melayu. Implikasi bagi kajian ini ialah; pembelajaran abad ke-21 memberikan kesan yang positif terhadap sikap dan motivasi pelajar dan seterusnya meningkatkan pencapaian mereka dalam pembelajaran Bahasa Melayu.

Kemahiran abad ke-21 berupaya menyediakan generasi baharu untuk berhadapan dengan sebarang kemungkinan yang timbul dalam warga industri, ekonomi global, Perubahan pesat teknologi, limpahan maklumat dan penggunaan computer sebagai satu keperluan dalam kehidupan seharian. Rusdi \& Ali [9] dalam kajian mereka yang bertajuk Amalan dan Cabaran Pelaksanaan Pembelajaran Abad ke-21 telah menjalankan kajian secara kualitif yang melibatkan seramai 20 orang guru bagi mengetahui pandangan mereka terhadap pelaksanaan pembelajaran abad ke-21 dalam amalan pengajaran mereka. Kajian ini menggunakan instrument kaedah soal selidik soalan terbuka yang telah dikendalikan bersama-sama perserta kajian untuk mengumpul maklumat berkaitan empat isi utama iaitu:

1. Pandangan guru

2. Amalan pengajaran

3. Kekangan dan cabaran

4. Cadangan penambahbaikan berhubungan pelaksanaan pembelajaran abad ke-21.

Dalam kajian ini kesemua maklumbalas daripada peserta diterjemah dan dianalisis mengikut tema. Daripada kajian yang dijalankan didapati para guru mempunyai pandangan yang positif terhadap pembelajaran abad ke-21, namun pada masa yang sama mereka masih perlu membuat penambahbaikan dalam amalan pengajaran. Antara kekangan yang dialami oleh para guru adalah kekangan masa, pengetahuan yang terhad serta kemudahan teknologi maklumat dan komunikasi yang terhad. Dalam kajian ini, perserta turut menyumbang beberapa cadangan untuk menambah baik kesemua cabaran yang timbul antaranya adalah yang pertama merangkumi professionalism, yang kedua penyediaan keperluan dan kemudahan dalam proses PdP dan yang ketiga adalah penyediaan modul pengajaran dan akhir sekali meningkatkan kualiti dan kuantiti alat kemudahan TMK.

\subsection{Gaya Pembelajaran Koperatif}

Pembelajaran koperatif adalah merupakan aktiviti pembelajaran dalam kumpulan yang berstruktur dimana pembelajaran adalah bergantung kepada pertukaran maklumat secara sosial dalam kalangan ahli kumpulan. Ini bermaksud setiap murid adalah bertanggungjawab terhadap pembelajaran sendiri dan juga ahli kumpulannya [10]. Sementara itu menurut Johnson et. al. [11] pembelajaran koperatif adalah merupakan pembelajaran dalam sekumpulan murid yang terdiri daripada du ahingga empat orang murid yang bersifat heterogen bagi memaksimakan pembelajaran setiap ahli kumpulan bagi mencapai matlamat bersama. Pembelajaran koperatif sepertimana yang ditakrifkan oleh Slavin [12] pula membawa maksud strategi pengajaran melalui kumpulan kecil heterogen tang bersturktu dan sistematik. Slavin berpendapat bahawa pembelajaran koperatif adalah sesuai untuk diterapkan dalam semua matapelajaran serta kepada semua murid disetiap peringkat.

\subsubsection{Kajian-Kajian Luar Negeri}

Davidson [13] menyatakan bahawa dalam penyelidikan yang dijalankan di luar negeri, didapati proses pembelajaran yang menggunakan pendekatan ini adalah lebih berkesan dalam meningkatkan pencapaian akademik berbanding dengan pendekatan koservatif. Sementara itu menurut Slavin \& Pensri \& Krongthong [14] Pembelajaran koperatif turut memberikan impak positif dalam hubungan sisaial diantara kaum serta sikap dan minat terhadap pelajaran.

Johnson \& Johnson [15] telah membuat rumusan daripada sebanyak 375 kajian luar negeri yang dijalankan sepanjang tempoh 90 tahun dan mendapati bahawa pendekatan pembelajaran koperatif adalah kaedah yang paling efektif dalam situasi yang memerlukan kemahiran pemikiran aras tinggi, idea-idea dan kreativiti, aplikasi dalam dunia sebenar dan melibatkan banyak penyelesaian masalah. Hubungan yang lebih baik juga dapat terbentuk diantara individu. Ini termasuklah mereka yang mempunyai kebolehan dan keupayaan yang berbeza daripada segi intelek, etnik, kelas sosial dan juga 
secara fizikal. Dalam kajian oleh Nelson (1996) [16] mendapati pelaksanaan Pembelajaran Koperatif dalam matapelajaran sains, kimia dan teknologi telah berjaya menjadikan seseorang murid menjadi lebih gigih dan menghasilkan tugasan yang lebih berkualiti.

\subsubsection{Kajian-Kajian Dalam Negeri}

Di Malaysia, murid didapati lebih berminat dan berpendapat bahawa pembelajaran adalah lebih menyeronokan dengan kaedah pembelajaran koperatif. Pendekatan ini dikatakan dapat membentuk nilai-nilai murni, menjalinkan hubungan erat antara kaum dan dapat menyumbang ke arah peningkatan pencapaian akademik dalam kalangan para murid [17]. Kelebihan dalam kaedah ini menurut Cheah \& June [18] adalah murid dilatih untuk berkomunkasi, menguruskan konflik, memimpin dan membuat keputusan yang mana merupakan kemahiran sosial yang amat penting dalam dunia pekerjaan. Dalam kajiannya Gan [19] menyatakan bahawa murid berpendapat bahawa pendekatan pembelajaran koperatif adalah menyeronokan kerana ia memenuhi keperluan untuk berinteraksi bersama, mewujudkan suasana belajar yang lebih terjamin dan bebas dari tekanan. Gan juga mencadangkan bahawa pembelajaran koperatif sesuai sekali digunakan untuk menangani masalah penguasaan kemahiran asas matematik bagi murid-murid pelbagai tahap pencapaian.

Proses pembelajaran koperatif yang efektif terdiri daripada beberapa prinsip asas iaitu kebergantungan secara positif yang menuntut semua ahli saling bekerjasama, sikap tanggungjawab individu atas keperluan pencapaian sendiri serta membuat keputusan dan atau membina kepercayaan. Secara asasnya, pembelajaran koperatif merupakan satu kaedah yang dapat menggalakan perkembangan personality yang melibatkan input akademik melalui tugasan yang diberikan oleh guru.

Rata-rata guru mempunyai pandangan yang positif terhadap pembelajaran koperatif. Pembelajarna jenis ini dilihat sebagai pembelajaran yang efektif untuk diamalkan. Sementara itu, dalam kajian oleh Ramli [20] terhadap 54 orang pelajar tingkatan 5 yang mengambil matapelajara fizik bagi mengkaji tentang Keberkesanan pembelajaran koperatif model STAD dalam subjek fizik terhadap pencapai pelajar mendapati bahawa kaedah pembelajaran koperatif membantu dalam meningkatkan pencapaian pelajar dalam matapelajaran fizik.

\section{Metodologi Kajian}

Metodologi kajian merupakan suatu proses bagi melaksanakan sesuatu penyelidikan dan perolehan maklumat bagi melaksanakan suatu kajian. Bab ini menerangkan bagaimana kajian ini dijalankan dengan menghuraikan tentang reka bentuk kajian, pemilihan sampel, lokasi kajian, instrumen kajian dan prosedur kajian berkenaan implikasi gaya pembelajaran koperatif subjek sains bagi murid tahap dua di Sekolah Kebangsaan Bandar Baharu Rawang.

\subsection{Reka Bentuk Kajian}

Kajian ini menggunakan pendekatan kualitatif dengan pelaksanaan kaedah temu bual separa berstruktur untuk mengkaji implikasi gaya pembelajaran koperatif subjek sains bagi murid tahap dua di Sekolah Kebangsaan Bandar Baharu Rawang. Kajian yang bersifat kualitatif ini digunakan kerana ia membantu melihat sesuatu isu daripada perspektif responden dengan lebih mendalam. Kajian kualitatif ini juga membantu memahami dan mempelajari intipati makna dalaman menurut perspektif responden dengan lebih baik. Kaedah temu bual dipilih untuk melaksanakan kajian ini kerana sifatnya yang mempunyai versetaliti dan generalisasi. Temu bual mampu membantu pengkaji untuk melihat masalah yang dikaji dengan lebih mendalam. Pengkaji juga dapat melihat sikap, perspektif, nilai dan kepercayaan responden berkaitan dengan isu yang ditemu bual. Skop kajian ini meliputi bilangan responden yang kecil. Data yang dikumpulkan melalui kaedah temu bual secara dalam talian dirakam dan kemudian dianalisis secara manual.

\subsection{Sampel Kajian}

Bagi kajian kualitatif, skop kajian adalah kecil namun memenuhi kriteria dan banyak informasi yang diperlukan bagi menghasilkan kajian yang sistematik. Seorang guru sains di Sekolah Kebangsaan Bandar Baharu Rawang dipilih sebagai responden dalam kajian ini. Responden dipilih adalah kerana pengalaman beliau dalam bidang pendidikan selama 16 tahun. Reponden juga bertanggujawab dalam mengajar mata pelajaran sains untuk tahap 2 di sekolah tersebut. Responden diberi keterangan teliti tentang peranan beliau dalam kajian ini. Responden juga telah diberitahu bahawa segala maklumat yang diperolehi akan dirahsiakan dan hanya digunakan untuk tujuan kajian ini. Identiti responden 
dirahsiakan dan responden juga diberi borang persetujuan untuk menjadi sempel bagi kajian ini. Responden memberi kerjasama yang baik dan amat membantu dalam pelaksanaan kajian ini.

\subsection{Lokasi Kajian}

Kajian ini dijalankan di salah sebuah Sekolah Rendah Kebangsaan di daerah Gombak, Selangor. Lokasi kajian adalah di Sekolah Kebangsaan Bandar Baharu Rawang. Pemilihan sekolah ini adalah berdasarkan pemilihan responden yang dipilih dalam kajian ini yang mempunyai pengalaman mengajar selama 16 tahun dalam mata pelajaran sains tahap 2. Sekolah ini juga merupakan sekolah dua sesi yang terletak di luar bandar.

\subsection{Instrumen Kajian}

Dalam kajian ini instrumen yang diguna dalam kajian ini ialah temu bual. Dalam kajian ini, penyelidik hanya menggunakan satu instrumen sahaja dalam pengumpulan data iaitu temu bual. Soalan temu bual dibina berdasarkan persoalan kajian bagi kajian ini dan ia dibina untuk menjawab persoalan kajian. Kaedah temu bual ini dijalankan secara atas talian melalui medium Google meet. Sesi temubual tersebut dirakam atas persetujuan responden. Temu bual merupakan kaedah yang perlu digunakan untuk kita mengetahui pengalaman sesorang secara peribadi yang sukar untuk ditiru semula. Oleh itu, pengkaji melaksanakan temu bual mendalam secara separa berstruktur bagi membolehkan responden bebas berkongsi pengalaman yang telah dilalui namun dalam masa yang sama perkongsian ini masih terikat dengan skop kajian dan persoalan kajian yang hendak di kaji. Pengkaji membimbing responden memberikan respon dengan menggunakan teknik dan kemahiran mencungkil, konfrontasi, stimulasi, inkuiri, refleksi dan interpretasi, supaya data yang diperoleh mantap dan lengkap. Temu bual juga membantu pengkaji menganalisis interaksi bersama responden dan konteks yang dibincangkan implikasi gaya pembelajaran koperatif subjek sains bagi murid tahap dua di Sekolah Kebangsaan Bandar Baharu Rawang. Pendapat, luahan perasaan, kepercayaan responden dapat dianalisis semasa pelaksanaan temu bual. Temu bual yang dilaksanakan mempunyai soalan terbuka ini adalah untuk mendapatkan maklumat yang mempunyai validiti dan kebolehpercayaan.

\subsection{Prosedur Kajian}

Pengkaji membuat temujanji mengikut masa dan tarikh yang dijanjikan untuk mengadakan sesi temu bual mengunakan medium google meet. Pengkaji memberi taklimat ringkas kepada responden sebelum item kajian dikemukakan. Pertama sekali tujuan temu bual dijelaskan dan kebenaran diperoleh untuk menemu bual responden. Borang persetujuan juga diberi kepada responden untuk mendapatkan persetujuan. Soalan yang ditanya kepada responden menepati persoalan kajian dan temu bual dilaksanakan secara separa stuktur. Responden ditemu bual untuk mendapatkan maklumat terperinci tentang persoalan kajian yang dikaji. Data dikumpul secara temu bual mendalam dengan melibatkan guru sains yang mengajar di tahap 2. Sesi temu bula dirakam dan direkodkan atas pengetahuan responden. Data yang dikumpulkan dari sesi temubual pengkaji dianalisis secara manual oleh pengkaji.

\section{Dapatan Kajian dan Perbincangan}

Perbincangan mengenai data kualitatif yang diperolehi oleh pengkaji, adalah merangkumi segala tujuan, objektif dan persoalan kajian ini. Kesemua data yang diperolehi adalah daripada sumber primer. Setiap data atau maklumat yang diperolehi daripada sesi temu bual tersebut adalah interpretasi penyelidik.

\subsection{Dapatan Kajian}

Analisis penyelidikan ini adalah tertumpu kepada beberapa persoalan yang telah dinyatakan dalam Bab 1 yang mana ia bertujuan untuk melihat skop implikasi gaya pembelajaran koperatif terhadap pembelajaran subjek Sains bagi murid tahap 2. Setiap persoalan tersebut telah dijawab oleh responden melalui temubual dalam talian menggunakan medium Google Meet.

\subsubsection{Soalan Kajian 1}

Apakah aktiviti pembelajaran koperatif yang sering dilaksanakan dalam subjek sains bagi murid tahap 2? 
Menurut respoden, antara aktiviti pembelajaran koperatif yang sering dijalankan dalam mata pelajaran sains adalah pembelajaran aktiviti secara dalam kumpulan dan juga aktiviti ujikaji eksprimen. Mata pelajaran sememangnya menjalankan aktiviti secara berkumpulan kerana topik yang dipelajari banyak menjalankan aktiviti berbentuk praktikal, eksperimen dan hands on. Tambahan lagi, aktiviti berkumpulan adalah antara gaya pembelajaran koperatif yang menjadi kecenderungan murid dimana terdapat perkongsian ilmu diantara para murid dan juga cambahan idea serta pendapat dapat dikongsikan bersama. Selain itu, aktiviti pembelajaran koperatif secara berkumpulan ini juga boleh membantu para murid berkongsi kemahiran dan memberi kritikan yang membina antara satu sama lain untuk kebaikan bersama sebagaimana pernyataan guru tersebut iaitu:

....gaya pembelajaran cara koperatif atau kolaborasi ni amat sesuai dalam pembelajaran Sains, kerana di sini ada perkongsian ilmu, dan cambahan idea serta pendapat yang dapat dikongsikan. Aktiviti mengeksperimen ini sememangnya menekankan pembelajaran koperatif, duduk sekumpulan, kongsi alat radas, tukar pendapat dan idea, kumpul data seterusnya dapat selesaikan masalah.

\subsubsection{Soalan Kajian 2}

Bagaimana gaya pembelajaran koperatif memberi impak terhadap murid dan pengurusan bilik darjah?

Berdasarkan jawapan daripada responden, adalah positif bahawa gaya pembelajaran koperatif memberi impak terhadap murid dan pengurusan bilik darjah. Menurut penerangan responden, mata pelajaran sains kebiasaannya dijalankan di bilik khas iaitu Bilik Sains. Di dalam Bilik Sains ini, murid perlu duduk secara berkumpulan kerana meja yang susun atur meja telah di tetapkan sebegitu. Oleh yang demikian, ia secara langsung memberi impak akan pembelajaran secara koperatif di dalam bilik darjah. Gaya pembelajaran koperatif dalam stimulus sosiologi ini sememangnya menjadikan murid terlibat dalam aktiviti berkumpulan. responden juga mengatakan kumpulan yang dibahagikan dalam aktiviti pembelajaran didalam kelas beliau adalah murid yang mempunyai gaya pembelajaran yang pelbagai. Namun murid yang cenderung dengan gaya stimulus sosiologi secara kolaboratif ini aktif dan berinteraksi dengan murid lain dengan berkesan apabila aktiviti kolaboratif dilaksanakan sebagaimana pernyataan guru sains sebagaimana berikut:

... kemahiran menyoal, dan mengkritik secara positif terhadap kumpulan pembentang tu lah. Jadi kat situ, berlaku kemahiran interaksi dan kemahiran bersosial, supaya tiada pergaduhan di situ. Jadi dalam jangka masa panjang, mereka dah tau step dia. So takde masalah. Saya akan bagi mark.

\subsubsection{Soalan Kajian 3}

Bagaimanakah guru dan murid memainkan peranan dalam PdPc bagi gaya pembelajaran ini? Menurut responden, peranan guru semasa aktiviti pembelajaran koperatif dilaksanakan dalam PdPc adalah sebagai fasilitator. Dimana guru sebagai pemudahcara, pembimbing kepada para murid ketika aktiviti dijalankan. Bagi murid pula, guru haruslah memberi peranan kepada murid supaya murid boleh kekal aktif dalam aktiviti pembelajaran. Kata beliau, guru perlu beri peranan kepada murid supaya murid tidak pasif dan tidak terlalu aktif. Peranan yang diberikan perlu ditukar dari masa ke semasa. Contoh peranan yang diberikan kepada murid adalah sebagai ketua kumpulan, pembentang, ahli jawatankuasa dan sebagainya. Peranan yang diberi diubah memgikut kesesuaian aktiviti pembelajaran koperatif.

\subsubsection{Soalan Kajian 4}

Sejauh manakah keberkesanan dan kesan pembelajaran koperatif kepada murid?

Menurut resonden, antara keberkesanan dan kesan pembelajaran koperatif kepada murid adalah dengan kebolehan meningkatkan kemahiran berkomunikasi murid dalam membentangkan pendapat, selain itu, perkongsian dalam kemahiran, memberi peluang kepada semua murid dalam aktiviti yang dijalankan. Tambahan lagi, pembelajaran koperatif membolehkan murid bertukar pendapat dan idea secara berkumpulan dan seterusnya dapat menyelesaikan masalah dalam aktiviti yang dilaksanakan. 


\subsection{Perbincangan}

Berdasarkan dapatan kajian yang telah dianalisis dan diproses mengikut objektif kajian yang telah dibuat, didapati bahawa kaedah pembelajaran koperatif dapat menarik minat serta pemahaman murid tahap dua dalam mata pelajaran Sains, seterusnya dapat membantu meningkatkan pencapaian mereka dalam subjek ini. Dengan menggunakan pembelajaran koperatif dalam aktiviti pengajaran dan pembelajaran, murid tahap dua dapat meningkatkan prestasi pencapaian dalam mata pelajaran Sains. Mereka juga akan merasa seronok dan dapat berkomunikasi secara efektif dalam kumpulan semasa mempelajari topik tertentu.

Selain itu, murid bukan dapat meningkatkan kefahaman terhadap topik yang diajar malah dapat menggunakan pengetahuan yang baharu diperoleh daripada pembelajaran secara koperatif untuk menyelesaikan masalah atau eksperimen yang dijalankan dengan lebih yakin. Aktiviti yang dijalankan secara berkumpulan dapat membantu murid dalam bertukar pendapat, berkongsi ilmu dan idea. Disamping itu, setiap kritikan yang membina akan diberi oleh rakan lain dapat membantu murid yang lemah meningkatkan daya pemikiran atau mencuba gaya pembelajaran yang lain. Oleh itu, pembelajaran menggunakan pembelajaran koperatif adalah perlu diamalkan dan digalakkan dalam mata pelajaran Sains untuk murid tahap dua.

Pembelajaran koperatif adalah berpusatkan murid. Oleh yang demikian, penglibatan setiap murid amat penting dalam melakukan aktiviti semasa PdPc. Pembelajaran yang dijalankan secara berkumpulan dan ia merupakan pembelajaran dan murid perlu bekerjasama untuk belajar dan bertanggungjawab ke atas setiap ahli kumpulannya. Setiap ahli kumpulan mempunyai tahap kemampuan yang berbeza-beza oleh itu semasa aktiviti ini murid dapat meningkatkan kemahiran berfikir secara kritis seperti kebolehan membuat, mentafsir dan menilai data, idea dan maklumat untuk mencari makna atau menyelesaikan masalah. Mereka juga dapat memperluas dan mengembangkan daya imaginasi, kreativiti, dan inovasi dengan tujuan mendapat idea baharu dalam menyelesaikan tugasan yang diberikan oleh guru.

\section{Rumusan}

Pembelajaran abad ke-21 seperti kaedah pembelajaran koperatif amat penting bagi membantu murid dalam meningkatkan tahap motivasi dan pencapaian murid dalam semua mata pelajaran. Dapatan dan implikasi daripada kajian ini juga menunjukkan pengaruh pembelajaran abad ke 21 ini banyak memberikan pengaruh yang positif terhadap sikap, motivasi dan pencapaian murid dalam mempelajari subjek yang tertentu. Tambahan pula, guru sebagai pembimbing perlu lebih kreatif dan bersedia di dalam proses pengajaran dan pembelajaran dengan mengadakan pelbagai aktiviti yang dapat menarik minat murid dalam memahami sesuatu topik.

Terdapat lima prinsip dan elemen yang perlu ada dalam PdPc yang menggunakan pembelajaran koperatif iaitu kebergantungan positif dimana setiap murid dalam kumpulan yang sama mempunyai peranan masing-masing dalam kerja berkumpulan. Dalam memperkukuhkan kebergantungan positif ini, jumlah ganjaran yang diperoleh oleh semua ahli kumpulan, pembahagian mencari maklumat untuk tugasan dan peranan ahli kumpulan sebagai pendorong satu sama lain perlu diberi penekanan. Prinsip yang kedua adalah akauntabiliti individu iaitu sikap bertanggungjawab kepada seseorang atau terhadap sesuatu tindakan perlu ada dalam diri murid untuk menyebarkan maklumat kepada rakan dan menguasai semua perkara yang perlu dipelajari bagi menjamin kejayaan sesuatu kumpulan. Setiap kumpulan perlu mengetahui ahli yang memerlukan lebih bantuan, sokongan dan galakan dalam menyiapkan sesuatu tugasan. Ketiga, interaksi muka ke muka dimana tugasan yang diberikan oleh guru perlu interaktif dengan memberikan maklum balas atau kesimpulan yang kritis dan yang paling penting ialah mereka saling mengajar, membantu, memberi dorongan dan sokongan dalam pembelajaran untuk mencapai matlamat kumpulan. Prinsip yang keempat adalah penggunaan kemahiran sosial. Kejayaan usaha secara koperatif memerlukan kemahiran sosial seperti interpersonal dan kemahiran kumpulan kecil. Murid perlu diajar kemahiran kepimpinan, membuat keputusan, komunikasi dan pengurusan konflik perlu juga dibimbing selari dengan kemahiran dalam akademik. Prinsip atau elemen yang terakhir yang perlu didalam PdPc adalah proses berkumpulan diamana ia berlaku apabila ahli kumpulan berbincang sejauh mana cara mereka mencapai matlamat dan mengekalkan kerja berkumpulan. Mereka perlu berbincang mengenai tindakan yang ahli kumpulan telah lakukan sama ada membantu atau tidak dan mengenalpasti perubahan yang perlu dilakukan supaya ia lebih efektif pada masa akan datang. Murid juga diberikan masa dan prosedur untuk menganalisis pembelajaran secara berkumpulan sama ada berfungsi sebaiknya atau tidak. Sejajar 
Nadia Abdul Rahim, Nor Aqilah Meor Fadzir, Nur Adilah Hani Zaimal, Firli Fairulyzan Arias Yahaya, Zatul Iffah Zainol, Mohd Razimi Husin.

dengan usaha untuk menghasilkan pembelajaran koperatif yang berkesan, guru juga perlu memahami prinsip dan elemen asasnya dalam menerapkan pembelajaran koperatif dalam PdPc.

\section{Rujukan}

[1] D. M. Kagan. "Measurements of Divergent and Complex Thinking," Educational and Psychological Measurement, vol. 48, no. 4, 1988. https://doi.org/10.1177/0013164488484002

[2] R. E. Slavin, "Research On Cooperative Learning and Achievement: What We Know, What We Need To Know," Contemporary Educational Psychology, pp 43-69. 1996.

[3] D. W. Johnson, and F. Johnson, Joining Together: Group Theory and Group Skills (4th Ed.) Englewood Cliffs. NJ: Prentice Hall, 1991.

[4] F. Firdaus \& K. Ismail, Md. Bakar, and B. Bakry, "Developing Critical Thinking Skills of Students in Mathematics Learning," Journal of Education and Learning (EduLearn), vol. 9. no. 226, 2015. doi:10.11591/edulearn.v9i3.1830.

[5] O. Kamisah, H. I. Zanaton, and H. Lilia, "Sikap terhadap sains dan sikap saintifik di kalangan pelajar sains," Jurnal Pendidikan, vol. 32, pp.39-60, 2007.

[6] Md. N. B. Bakar \& S. M. B. Syed Mohamad, Masalah Pembelajaran Pelajar Sekolah Menengah Dalam Mata Pelajaran Sains Tingkatan 2 Tajuk: Fotosintesis. Johor: Universiti Teknologi Malaysia, 2017.

[7] A. Adam, "Faktor Keberkesanan Guru Cemerlang Sains Dalam Proses Pengajaran dan Pemudahcaraan," National Conference of Educational Research, 2019.

[8] A. R. Iberahim, Z. Mahamod, and W. M. Mohamad, "Pembelajaran Abad Ke-21 dan Pengaruhnya Terhadap Sikap, Motivasi dan Pencapaian Bahasa Melayu Pelajar Sekolah Menengah," Jurnal Pendidikan Bahasa Melayu, vol. 8, pp. 77-88, 2017

[9] N. M. Rusdin, and S. R. Ali, "Amalan dan Cabaran Pelaksanaan Pembelajaran Abad ke-21. International Conference on Islamic Civilization and Technology Management," Research Institute for Islamic Product and Malay Civilization (INSPIRE), 2019.

[10] R. E. W. B. Olsen and S. Kagan, About Cooperative Learning. In C. Kessler (Ed.), Cooperative Language Learning: A Teacher's Resource Book. Englewood Cliffs, NJ: Prentice Hall, 1992.

[11] D. W. Johnson, and F. Johnson \& E. J. Holubec, Circle of learning: Cooperation in the Classroom (3rd Ed.). Edina, Minnesota: Interaction Book, 1990.

[12] R. E. Slavin, Cooperative Learning: Theory, Research, and Practice. Englewood Cliffs, New Jersey: Prentice Hall, 1990.

[13] D. Davidson, "Incoherence and Irrationality," dialectica, vol. 39, no. 4, pp. 345-354, 1985.

[14] T. Pensri and K. Krongthong, "Cooperative Learning In Mathematics," in SEAMEO Regional Centre for Education in Science and Mathematics, Penang, Malaysia, 1995.

[15] R. T. Johnson and D. W. Johnson, "Active Learning: Cooperation in the Classroom," The Annual Report of Educational Psychology in Japan, vol. 47, pp. 29-30, 2008. 10.5926 /arepj1962.47.0_29

[16] K. Nelson, Language in Cognitive Development: Emergence of the Mediated Mind. Cambridge University Press, 1996.

[17] R. L. Oxford, "Cooperative Learning, Collaborative Learning, and Interaction: Three communcative Strands in the Language Classroom," The Modern Language Journal, pp. 443456, 1997.

[18] L. N. Cheah and M. L. June Poon, "Efficacy of Cooperative Learning Among Malaysian Secondary School Students," Journal of School of Educational Studies, vol. 16, pp. 13-27, 1999.

[19] T. H. Gan, "Mencari titik perseimbangan di antara keunggulan teori dan kenyataan praktis: Satu kes pelaksanaan Penyelidikan pembelajaran koperatif dalam pengajaran matematik sekolah rendah," Jurnal Penyelidikan Pendidikan MPS, vol. 2, pp. 68-85, 1999.

[20] N. Ramli, Keberkesanan pembelajaran koperatif model student teamsachievement divisions (stad) dalam fizik terhadap pencapaian pelajar, 2019. Available: http://eprints.uthm.edu.my/ id/eprint/ 9102/1/Noraziah_Ramli.pdf. [Accessed: 2021]. 